EDITORIAL

\title{
Educação em Ciências e Educação em Saúde: breves apontamentos sobre histórias, práticas e possibilidades de articulação
}

\author{
Isabel Martins ${ }^{1}$ \\ https://orcid.org/0000-0001-5572-6958
}

Tópicos relacionados à saúde têm sido, historicamente, objeto de trabalho curricular em diversos momentos da educação brasileira. Segundo as revisões de Mohr e Schall (1992), esforços nesta direção datam do início do século XX e estão marcados por fatores contextuais. De fato, um olhar histórico permite compreender que, ao longo dos anos, tais esforços refletem formas particulares de compreensão dos conceitos de educação e de saúde.

O início do século XX marca o início sistemático da introdução de abordagens de educação em saúde nos programas escolares. Nesta época, identificamos uma série de fatores contextuais, internos e externos às áreas da saúde e da educação. São exemplos de fatores internos à área da saúde: o desenvolvimento de descobertas bacteriológicas ao longo do século XIX; a ênfase na doença e a influência do pensamento positivista ao tentar compreendê-las por meio de relações de causa e efeito; o impacto do relatório Flexner, datado de 1910, que influenciou fortemente a formação médica no século XX, argumentando a favor de metodologias científicas rigorosas e desconsiderando a relevância de fatores sociais no entendimento do processo saúde-doença. Estes fatores constituem a base de perspectivas higienistas para a educação em saúde, na qual a melhoria de condições sanitárias é vista como fator preponderante na eliminação dos focos de doença, e que estão tipicamente presentes nos documentos que orientam práticas escolares em saúde nesta época. Tal visão possui uma contrapartida em visões educacionais que valorizam a ordem e a disciplina, por meio do controle dos espaços e dos corpos como forma de criar condições para a aprendizagem (COLLARES; MOYSÉS, 1985). É no seu bojo que são instituídas, na primeira metade do século XX, as orientações nutricionais para a merenda escolar, os exames antropométricos e a valorização da prática de exercícios físicos (LIMA, 1985 apud MONTEIRO; BIZZO, 2015, p. 412-413). Desta forma, tais visões de educação e de saúde confluem em práticas higienistas e de controle sanitário no cenário sócio-político do início do século XX, marcado por preocupações com as consequências da industrialização, seu efeito no crescimento das cidades e no surgimento de doenças (GHIRALDELLI JUNIOR, 1988).

As perspectivas higienistas permanecem presentes nos espaços escolares, mas passam a ser questionadas em meados do século XX. Neste período iniciam-se contestações à visão predominantemente curativa da Medicina em favor de uma visão preventiva, que considera aspectos ambientais e epidemiológicos no entendimento da relação saúde-doença. Tal visão equaciona

\footnotetext{
1 Universidade Federal do Rio de Janeiro (UFRJ), Instituto Nutes de Educação em Ciências e Saúde, Rio de Janeiro, RJ, Brasil. E-mail: isabelmartins@ufrj.br
} 
a saúde como um conjunto de capacidades físico-funcionais e de bem-estar físico e mental dos indivíduos e destaca a necessidade de mudanças de comportamento para adoção de estilos de vida saudável (WESTPHAL, 2006). No entanto, embora ampliem a conceituação de saúde, continuam a focalizar no indivíduo. São as abordagens socioambientais, identificadas com políticas de saúde inspiradas pelo relatório Lalonde (1974) e pelas discussões realizadas nas Conferências Mundiais de Saúde (BRASIL, 2002), que passarão a incluir aspectos socioeconômicos, educacionais, culturais, políticos e psicológicos, para além dos biológicos como fatores determinantes de saúde dos indivíduos e tratar a capacitação/empoderamento e a participação efetiva na promoção de saúde como um recurso para melhores condições de vida (LIMA; MOREIRA, 2012).

Estes debates travados no campo da saúde ocorrem concomitantemente a momentos nos quais conceitos de educação, que expressam visões antagônicas, são tensionadas, por exemplo, nas décadas de 1960 e 1970. Neste período, temos, por um lado, uma conceituação na qual a educação é entendida como um instrumento de controle e reprodução social, pautando-se no desenvolvimento de hábitos, na normatização de comportamentos e na possibilidade de ajuste e adaptação dos indivíduos na sociedade (BOURDIEU; PASSERRON, 1992). Por outro lado, encontramos formulações nas quais a educação é concebida como um ato político que objetiva a transformação social na direção de uma sociedade mais democrática e igualitária, identificadas com perspectivas emancipatórias e transformadoras da sociedade (FREIRE, 1987). Podemos estabelecer relações entre distintas concepções e possibilidades de articulação entre conceitos de saúde e de educação. De fato, tanto há perspectivas e tendências no campo caracterizadas por princípios e práticas de inspiração crítica, quer dizer, voltadas à construção de formas de transformação social, quanto aquelas que estão associadas a estratégias de controle e de ajuste dos indivíduos a padrões normativos.

Os aspectos históricos não são os únicos a serem mobilizados quando da caracterização dos campos da educação e da saúde, e de suas relações. Por exemplo, considerações do ponto de vista epistemológico são importantes ao atentarmos para as especificidades do estatuto e das práticas de produção de conhecimento nos dois campos. Não menos importante é o fato de que, do ponto de vista da construção de cada um destes campos científicos sob um olhar sociológico, percebemos uma relativa independência no que diz respeito à constituição e à configuração das comunidades científicas da educação e da saúde, dado que cada uma possui suas próprias regras de pertencimento, vinculações institucionais, veículos de produção científica, entre outros aspectos que caracterizam os campos científicos (BOURDIEU, 2004).

A pluralidade das articulações entre educação e saúde está marcada nas diferentes formas pelas quais o próprio campo se autodenomina, a saber, "educação para a saúde”, "educação popular em saúde”, "educação e saúde”, "educação em saúde”, "educação na saúde”, entre outras. Refletindo sobre as implicações de tal diversidade para o campo da Saúde Coletiva, Falkenberg et al. (2014) discutem diferentes sentidos para cada uma delas. Para as autoras, a expressão educação para a saúde pode denotar uma concepção verticalizada de educação na qual profissionais de saúde ensinam a população ignorante a adotar hábitos saudáveis enquanto educação popular em saúde organiza-se a partir da aproximação com os sujeitos

[...] no espaço comunitário, privilegiando os movimentos sociais locais, num entendimento de saúde como prática social e global e tendo como balizador ético-político os interesses das classes populares. Baseia-se no diálogo com os saberes prévios dos usuários dos serviços de saúde, seus saberes 'populares', e na análise crítica da realidade (FALKENBERG et al., 2014, p. 849). 
Ainda para as mesmas autoras, educação e saúde sugere "[...] um paralelismo entre as duas áreas, com separação explícita dos seus instrumentos de trabalho: a educação ocupando-se dos métodos pedagógicos para transformar comportamentos e a saúde dos conhecimentos científicos capazes de intervir sobre as doenças" (FALKENBERG et al., 2014, p. 848). As autoras contrastam esta visão com aquela presente na formulação educação em saúde, caracterizada como um processo político pedagógico que envolve diferentes profissionais e setores da sociedade, cujo objetivo é aumentar a autonomia dos indivíduos nas escolhas e decisões acerca de questões individuais e coletivas envolvendo saúde. Finalmente, destacam a ênfase nas questões relacionadas à formação profissional e na educação permanente de profissionais de saúde que caracteriza as abordagens de educação na saúde.

Intencionalmente, até agora nos referirmos a este campo como educação em saúde. Ao fazê-lo ressaltamos o compromisso com a educação, em suas relações com as demais ciências humanas e sociais, como referência teórico-metodológica central, caracterizando a saúde como recorte temático que dá contornos e especificidades à discussão educacional. Assim, afastamonos de uma visão generalista e instrumental da educação. Sugerimos que tal formulação, que consideramos próxima da pauta da área de Educação em Ciências, pode potencialmente ampliar a agenda da Educação em Saúde em termos de focos de interesse e escopo de investigações, promovendo articulações entre espaços de intervenção e áreas de saber, e apontando para a possibilidade de compreender o campo em termos de objetos e tentativas de teorização próprias. Por outro lado, para a Educação em Ciências, o diálogo com a Educação em Saúde pode reforçar a necessidade de considerar de forma explícita o papel das políticas públicas em educação e em saúde na formulação e no tratamento de questões de investigação. Além disso, pode proporcionar a concretização de cenários relevantes de contextualização e de interdisciplinaridade, bem como deslocamentos que permitam revisitar discussões acerca de formação em espaços de prática, por exemplo, por meio de análises de modelos de formação para a docência e para a assistência, como as residências. De fato, são muitas as referências comuns aos campos. Por exemplo, a educação popular em saúde, fortemente inspirada pelos movimentos de educação popular (STRECK; ESTEBAN, 2013) foi, segundo Vasconcelos, Vasconcelos e Silva (2015), apropriada em várias políticas públicas de saúde. Já as orientações curriculares para a educação básica constantes nos Parâmetros Curriculares Nacionais (PCN) estabeleceram o tema saúde como transversal à educação básica e a educação como estratégia de promoção de saúde (BRASIL 1997). Tais considerações apontam para benefícios mútuos advindo das aproximações entre áreas. Estes têm sido potencializados por contextos institucionais, notadamente a área de conhecimento 46 (ensino) da Coordenação de Aperfeiçoamento de Pessoal de Nível Superior (CAPES), na qual encontramos quase que desde sua origem, programas de pós-graduação em Educação em Saúde, e a abertura para apresentação e publicação de trabalhos de Educação em Saúde em eventos e periódicos da área de Educação (em Ciências), respectivamente.

$\mathrm{O}$ argumento de que os campos da educação (em ciências) e da saúde têm histórias próprias e trajetórias singulares que, no entanto, admitem diálogos e interseções, revela não só os potenciais benefícios, mas também sugere importantes desafios. Segundo Mohr e Schall (1992), mesmo após a implantação da obrigatoriedade da Educação em Saúde no Brasil, ocorrida formalmente por meio da Lei de Diretrizes e Bases da Educação 5692/71, as ações de Educação em Saúde não se consubstanciaram nos resultados desejados. Para as autoras, inúmeros fatores concorrem para isso, notadamente, o despreparo dos professores, as limitações dos livros didáticos e inadequações metodológicas no tratamento curricular de conteúdos de saúde. Especificamente, em relação aos Programas de Saúde, afirmam que estes, 
[...] paradoxalmente, tem sua ênfase na doença e não na saúde. Como resultado, verifica-se que os conhecimentos que são pretensamente desenvolvidos com os alunos não são traduzidos em comportamentos, seja por falta de condições de internalização dos conteúdos ou porque estes não possuem significado para a realidade do estudante. (MOHR; SCHALL, 1992, p. 201).

As autoras também destacam que, a exemplo do que ocorre com algumas propostas da educação ambiental, as discussões sobre saúde estão desvinculadas da realidade social dos alunos, dificultando questionamentos sobre causas e consequências dos problemas que enfrentam e a sequente promoção de práticas de cidadania.

Trabalhos mais recentes sugerem, entretanto, tentativas de um tratamento mais integrado e crítico das questões de saúde nos currículos escolares. Em suas análises de documentos de políticas públicas que orientam a abordagem da saúde na escola, Monteiro e Bizzo (2015, p. 425) destacam “[...] importantes avanços e mudanças na compreensão da saúde, a partir da incorporação de seus determinantes sociais, da ideia de direito à saúde e da incorporação da dimensão coletiva aos objetivos da educação para a saúde". No entanto, a exemplo de Freitas e Martins (2008), chamam atenção para a necessidade de que o trabalho escolar em saúde possa ser pautado pela criticidade necessária às demandas por transformação e justiça social. Tais ressalvas são também reforçadas em análises de documentos curriculares contemporâneos, como a Base Nacional Comum Curricular (SOUSA; GUIMARÃES; AMANTES, 2019).

Ainda no que diz respeito ao campo da Educação em Ciências, podemos identificar tentativas que buscam avançar no sentido de uma educação em saúde em que esta é entendida como direito e como elemento fundamental nos processos de tomada de decisão, individual e coletiva. Alguns exemplos incluem as aproximações entre educação em saúde e formação de professores (VENTURI; MOHR, 2017), as análises de livros didáticos pautadas em perspectivas discursivas críticas (PINHÃO; MARTINS, 2012; VILANOVA; MARTINS, 2008), articulações com pressupostos Ciência-Tecnologia-Sociedade (CTS) em contextos de uso de tecnologias digitais de informação e comunicação (STRUCHINER; GIANELLA, 2016) e relações entre letramento científico e educação em saúde (MARTINS, 2011).

De fato, tomando como parâmetro o número de trabalhos apresentados nas últimas edições do Encontro Nacional de Pesquisa em Educação em Ciências (ENPEC), percebemos a regularidade e o crescente interesse da comunidade de Educação em Ciências por temas relacionados à saúde, desde meados da década de 2000. Foram apresentados cinco trabalhos que tratavam de temáticas relacionadas à saúde no III ENPEC em 2001, 13 trabalhos no IV ENPEC em 2003, 46 trabalhos no V ENPEC em 2005, 21 trabalhos no VII ENPEC em 2009, 51 no VIII ENPEC em 2011, 64 no IX ENPEC em 2013, 46 no X ENPEC em 2015, e 63 no XI ENPEC em 2017. Estes tratam dos mais variados temas, por exemplo, alimentação, educação sexual, gênero, endemias e doenças crônicas. Outros temas de interesse encontrados na literatura incluem segurança alimentar, soberania alimentar, dependência de drogas, engenharia genética, depressão, e doenças mentais. Uma análise das abordagens para tais questões de saúde reforça a tese de que estas se distribuem em um espectro que vai desde aquelas que defendem o estabelecimento de comportamentos normativos, até aquelas que visam a fomentar o desenvolvimento de práticas autônomas. Algumas remetem-se a perspectivas funcionais, que ressaltam o ajuste e a contribuição para a sociedade como objetivo da educação, enquanto outras enfatizam perspectivas críticas, baseadas no questionamento e nas possibilidades de transformação da sociedade. Assim, além de relacionarem-se a diferentes concepções sobre objetivos e propósitos da educação, refletem também a polissemia inerente ao conceito de saúde em diferentes contextos 
que informaram a educação em saúde, a saber: abordagens higienistas, prevenção de doenças, determinantes sociais da saúde, promoção da saúde, saúde, etc. Tal pluralidade de sentidos, associada às possíveis relações entre a saúde e diferentes áreas de conhecimento, bem como sua forte conexão com contextos da vida social e com práticas de tomada de decisão, reforça o argumento a favor da potencial produtiva interface entre Educação em Ciências e Educação em Saúde, que explora, por exemplo, questões sócio-científicas e temas controversos. Sua discussão, em contextos educacionais, formais e informais, dialoga com objetivos relacionados à alfabetização científica, educação para a cidadania e educação (em ciências) para a justiça social.

Para além das experiências brasileiras, temos observado, nos últimos anos, um esforço consistente de produzir conhecimento relevante sobre educação em saúde no âmbito da América Latina. E grande parte acontece no contexto de disciplinas relacionadas à Educação em Ciências. Frequentemente elas articulam intervenção e investigação, baseando-se tanto em perspectivas teóricas sólidas quanto em práticas socioculturais contextualizadas. Atualmente, estamos envolvidas na edição de um livro coorganizado com Silvina Cordero da Universidade Nacional de La Plata, na Argentina, e Sandra Escovedo Selles, da Universidade Federal Fluminense, que reúne exemplos de como a pesquisa em educação em ciências tem interrogado a realidade social em relação a questões de saúde na Argentina, no Brasil, na Colômbia e no México. Por meio de uma variedade de gêneros textuais, como revisões sistemáticas de literatura, relatórios de pesquisa empíricos e ensaios, estudiosos latino-americanos oferecem reflexões baseadas em evidências, bem como relatos teorizados das maneiras pelas quais a educação em saúde foi historicamente construída em seus países nos últimos anos. Neste contexto, fazem referência a experiências de reformas curriculares, práticas e diretrizes para a formação de professores, elaboração e avaliação de materiais didáticos, práticas de popularização da ciência em espaços de educação não formal. Ao fazê-lo, estabelecem diálogos produtivos com tendências críticas e pós-críticas em educação, teoria sociocultural, políticas educacionais, temas e abordagens em saúde pública e em saúde coletiva, e estudos ambientais. Isso é feito de uma forma que aborda aspectos transculturais, bem como socioeconômicos e políticos da educação em saúde na América Latina, mas transcende especificidades regionais e preocupações específicas. O livro não pretende ser uma amostra representativa, e muito menos esgotar a variedade de abordagens e perspectivas sobre Educação em Saúde na região. Sua contribuição consiste em reunir exemplares de uma mistura interessante e produtiva entre estudos de investigação e intervenção, a fim de oferecer novos ângulos, análises de leituras de questões relacionadas à educação em saúde que, como muitos outros aspectos da vida social globalizada, atravessam países e culturas. Ao fazê-lo, não só os autores fornecem uma crítica informada sobre os aspectos teóricos subjacentes envolvidos na educação em saúde e mais insights sobre desafios locais, mas também provocam leitores não latino-americanos a considerar pontos de vista alternativos para problematizar e lidar com possíveis relações entre eles. Esperamos que este projeto, aprovado pela editora Springer e em fase de preparação, possa contribuir com mais elementos para a reflexão acerca das interfaces possíveis entre Educação e Saúde, no contexto da formação em ciências, em contextos formais e não formais.

\section{Referências}

BOURDIEU, P. Os usos sociais da ciência: por uma sociologia clínica do campo científico. São Paulo: Ed. UNESP, 2004.

BOURDIEU, P.; PASSERON, J. C. A reprodução: elementos para uma teoria do sistema de ensino. Rio de Janeiro: Francisco Alves, 1992. 
BRASIL. Ministério da Educação. Parâmetros curriculares nacionais: meio ambiente, saúde: $1^{\text {a a }} 4^{\mathrm{a}}$ séries. Brasília: MEC: SEF, 1997.

BRASIL. Ministério da Saúde. As cartas da promoção da saúde. Brasília: Ministério da Saúde, 2002. Disponível em: http:/ /bvsms.saude.gov.br/bvs/publicacoes/cartas_promocao. pdf. Acesso em: 22 maio 2019.

COLLARES, C. A. L.; MOYSÉS, M. A. A. Educação ou saúde? Educação x saúde? Educação e saúde! Cadernos Cedes, Campinas, n. 15, p. 7-16, 1985.

FALKENBERG, M. B.; MENDES, T. P. L.; MORAES, E. P.; SOUZA, E. M. Educação em saúde e educação na saúde: conceitos e implicações para a saúde coletiva. Ciência \& Saúde Coletiva, Rio de Janeiro, v. 19, n. 3, p. 847-852, 2014. DOI: https://doi.org/10.1590/141381232014193.01572013.

FREIRE, P. Pedagogia do oprimido. 17. ed. Rio de Janeiro: Paz e Terra, 1987.

FREITAS, E. O.; MARTINS, I. Concepções de saúde no livro didático de ciências. Ensaio: pesquisa em educação em ciências, Belo Horizonte, v. 10, n. 2, p. 235-256, 2008. DOI: https://doi.org/10.1590/1983-21172008100205.

GHIRALDELLI JÚNIOR, P. Educação física progressista: a pedagogia crítico-social dos conteúdos e a educação física. 6. ed. São Paulo: Loyola, 1988.

LALONDE M. A new perspective on the health of Canadians: a working document. Ottawa: Minister of Supply and Services Canada, 1974. Disponível em: http://www.phacaspc.gc.ca/ph-sp/pdf/perspect-eng.pdf. Acesso em: 22 maio 2019.

LIMA, A.; MOREIRA, M. C. Abordagens de saúde: o que encontramos nos livros didáticos de ciências. In: MARTINS, I.; GOUVÊA, G.; VILANOVA, R. O livro didático de ciências: contextos de exigência, critérios de seleção, práticas de leitura e uso em sala de aula. Rio de Janeiro: Faperj, 2012. p. 117-124.

MARTINS, I. Literacy as metaphor and perspective in science education. In: LINDER, C. et al. (org.). The landscape of scientific literacy. New York: Routledge: Taylor and Francis, 2011. p. 90-105.

MOHR, A.; SCHALL, V. T. Rumos da educação em saúde no Brasil e sua relação com a educação ambiental. Cadernos de Saúde Pública, Rio de Janeiro, v. 8, n. 2, p. 199-203, 1992. DOI: https://doi.org/10.1590/S0102-311X1992000200012.

MONTEIRO, P. H. N.; BIZZO, N. A saúde na escola: análise dos documentos de referência nos quarenta anos de obrigatoriedade dos programas de saúde, 1971-2011. História, Ciências, Saúde-Manguinhos, Rio de Janeiro, v. 22, n. 2, p. 411-427, 2015. DOI: http:// dx.doi.org/10.1590/S0104-59702014005000028.

PINHÃO, F; MARTINS, I. O discurso sobre saúde e ambiente no livro didático de ciências brasileiro. Revista Electrónica de Enseñanza de las Ciencias, Vigo, v. 11, n. 2, p. 342364, 2012. Disponível em: http://reec.uvigo.es/volumenes/volumen11/REEC_11_2_5_ ex595.pdf. Acesso em: 22 maio 2019. 
SOUSA, M. C.; GUIMARÃES, A. P. M.; AMANTES, A. A saúde nos documentos curriculares oficiais para o ensino de ciências: da lei de diretrizes e bases da educação à base nacional comum curricular. Revista Brasileira de Pesquisa em Educação em

Ciências, Beho Horizonte, v. 19, p. 129-153, 2019. DOI: https://doi.org/10.28976/19842686 rbpec2019u129153.

STRECK, D. R.; ESTEBAN, M. T. Educação popular: lugar de construção social coletiva. Petrópolis: Vozes, 2013.

STRUCHINER, M.; GIANNELLA, T. R. Com-viver, com-ciência e cidadania: uma pesquisa baseada em design integrando a temática da saúde e o uso de tecnologias digitais de informação e comunicação na escola. e-Curriculum, São Paulo, v. 14, n. 3, p. 942-969, 2016. Disponível em: https://revistas.pucsp.br/index.php/curriculum/article/view/28701. Acesso em: 22 maio 2019.

VASCONCELOS, E. M.; VASCONCELOS, M. O. D.; SILVA, M. O. A contribuição da educação popular para a reorientação das práticas e da política de saúde no Brasil. Educação e Contemporaneidade: revista da FAEEBA, Salvador, v. 24, n. 43, p. 89-106, 2015.

Disponível em: https://revistas.pucsp.br/index.php/curriculum/article/view/28701. Acesso em: 22 maio 2019.

VENTURI T.; MOHR, A. Aproximando pesquisa e prática docente: contribuições de um curso de formação de professores no tema da educação em saúde. Enseñanza de las Ciencias, Barcelona, p. 443-448, 2017. Número extraordinario. Trabalho apresentado no $10^{\circ}$ Congreso Internacional sobre Investigación en Didáctica de las Ciencias, 2017, Sevilla, España. Disponível em: https://www.raco.cat/index.php/Ensenanza/article/view/334437. Acesso em: 22 maio 2019.

VILANOVA, R.; MARTINS, I. Discursos sobre saúde na educação de jovens e adultos: uma análise crítica da produção de materiais educativos de ciências. Revista Electrónica de Enseñanza de las Ciencias, Vigo, v. 7, n. 3, p. 506-523, 2008. Disponível em: http:/ / reec. uvigo.es/volumenes/volumen7/ART1_Vol7_N3.pdf. Acesso em: 22 maio 2019.

WESTPHAL, M. F. Promoção da saúde e prevenção de doenças. In: CAMPOS, G. W. S. et al. (org.). Tratado de saúde coletiva. São Paulo: HUCITEC; Rio de Janeiro: Ed . Fiocruz, 2006. p. 635-68. 
